\title{
Robust Stabilization of a Non-Linear Chaotic Financial System with Uncertain Parameters
}

\author{
Santosh Kumar Choudhary \\ Department of Instrumentation \& Control Engineering \\ Manipal Institute of Technology, Manipal-576104, India \\ Corresponding author E-mail: santosh.kumar@manipal.edu
}

\begin{abstract}
The paper investigates an analytical approach for robust stabilization of nonlinear chaotic financial system in the presence of uncertain parameters. The primary focus of this paper is to find a robust solution for quickly adjusting and controlling the interest rate, investment demand and price exponent when the chaotic phenomenon occurs in the financial system or economic crisis happens. The paper first demonstrates the non-linear dynamical model of the chaotic financial system and then it adopts Lyapunov stability theory based adaptive control scheme for robust stabilization of nonlinear chaotic financial system in the presence of uncertain parameters. Numerical simulations are demonstrated to verify the effectiveness of the proposed control scheme. The simulation results of this paper show that control scheme successfully eliminates the chaos of the nonlinear financial systems
\end{abstract}

Keywords: Nonlinear system; Chaotic dynamical system; Financial system; Adaptive control; Lyapunov stability theory; Robust stabilization

\section{Introduction}

Chaos control was first introduced Edward Ott, Celso Grebogi and James A. Yorke [1] in 1990 and subsequently, several research works have been explored to develop chaos control frameworks for dynamical systems due to its potential applications in economics, financial systems and various fields of engineering and natural sciences (see articles $[2,3,4,5,6,7,8,9,10,11,12$, $13,14,15,16])$. The chaotic systems are very rich in dynamics and possess great sensitivity to initial conditions and this dynamic property is popularly known as the butterfly effect [17, 18]. In other words, if two trajectories emerging from two different closeby initial conditions of the system separate exponentially in the course of time, then it can produce an infinite number of dynamical behaviors (either periodic and not periodic), with the only help of tiny perturbations chosen properly $[17,19,1,20]$. The chaotic behavior is undesirable in any system, and it degrades entire system performance. Therefore, chaos of any dynamical system should be controlled or synchronized as much as possible.

The chaotic phenomenon often appears in the financial system during the economic crisis and it was first found in 1985 [21]. In 2007, the U.S. subprime mortgage crisis triggered the global economic crisis, which also shows the existence of the butterfly effect and chaos in the finance system [16]. If chaotic phenomenon occurs in the economic system or economic crisis happens, the macroeconomic operation can face uncertainty and indefiniteness [21]. Even though the government can adopt macrocontrol measures such as revising financial policies or the monetary policies to interfere, but the effectiveness of the interference is very limited. The instability and complexity make the precise economic prediction greatly limited, and the reasonable prediction behavior can become complicated as well [22]. Thus, chaos control of financial systems imposes a great impact on the research. It is an interdisciplinary area of research and has become a hot topic for many researchers within engineering, mathematical and economist communities. The classical goal of chaos control is to force a given financial system to show robustly a stable behavior. Controlling the chaos is more efficient and significant rather than synchronizing the chaos in many chaotic financial systems due to the sensitivity of economics chaos to the initial value. Several studies attempted to develop the control framework for chaotic financial systems [23, 24, 25, 26, 27 , $28,16]$. Linear feedback, speed feedback, selection of gain matrix, revision of gain matrix controllers [21], time-delayed feedback controllers [29] and single controller scheme [30] were used for the control of the chaotic financial system. The robust stabilization concept for a non-linear chaotic financial system with uncertain parameters via adaptive control scheme was not discussed in any of the literature. In this work, an analytical investigation on the robust stabilization of the nonlinear chaotic financial system is explored. The simulations result of this paper indicate that proposed control scheme is efficient way to adjust and control the interest rate, investment demand and price exponent when chaotic phenomenon appears in the non-linear financial system.

The rest of the paper is organized as follows: In section 2, threedimensional non-linear chaotic financial system is briefly explained, and chaotic behaviors of non-linear finance system are also demonstrated via basic system theory concept. Stabilization methodology for non-linear chaotic financial system is described in section 3 and section 4 deals with numerical simulation experiments and its results analysis to verify the effectiveness of the present study. The paper concludes in section 5 . 


\section{Illustration of Non-linear Chaotic Financial System Model}

This section briefly describes a non-linear chaotic financial system model. The contents presented in this section are self-explanatory and that help to illustrate the chaotic behavior of a non-linear financial system model.

\subsection{State Space Model of Chaotic Finance System}

Consider the following three-dimensional autonomous non-linear chaotic financial system model which consists of production, currency and labor force $[23,21,27,22]$ :

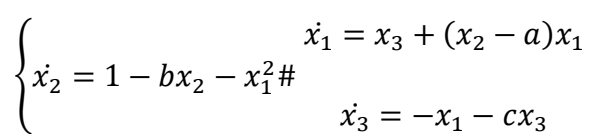

where $x_{1}, x_{2}$ and $x_{3}$ represent the interest rate, investment demand and price exponent or index respectively in the model.

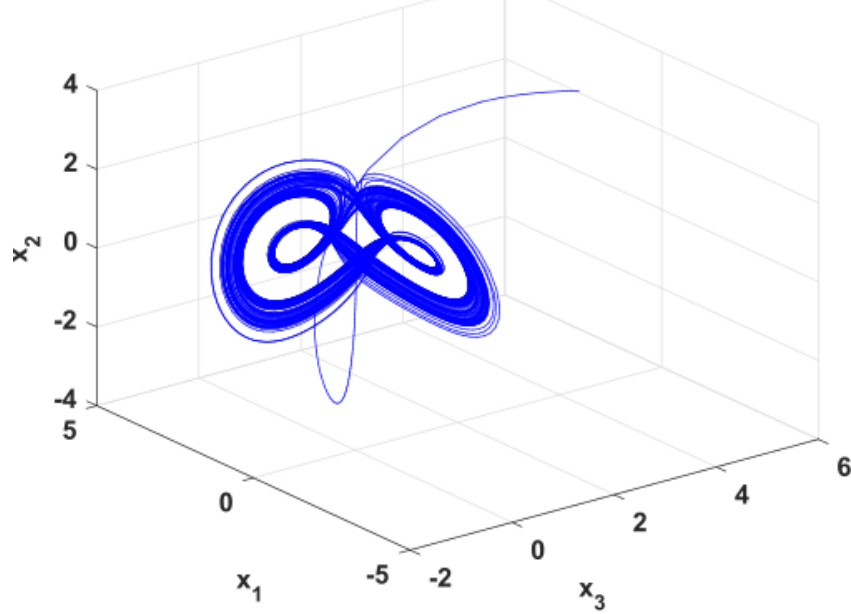

Fig: 1: 3D phase plane of $x 3, x 1$ and $x 2$ in the non-linear chaotic finance system

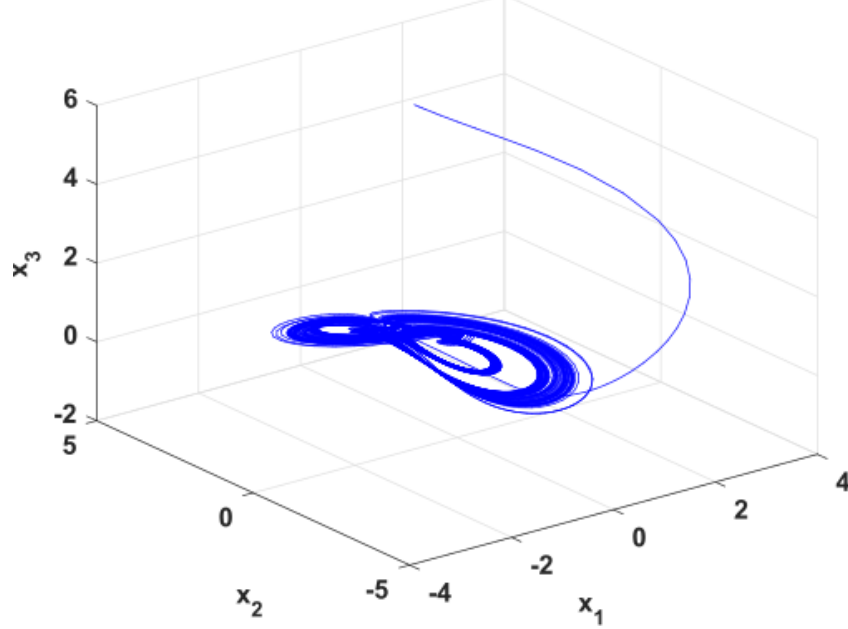

Fig. 2: 3D phase plane of $x_{1}, x_{2}$ and $x_{3}$ in the non-linear chaotic finance system

The model describes the time-variation of three state variables $x_{1}, x_{2}$ and $x_{3}$. The constants $a, b$ and $c$ are the uncertain parameters, but all are non-negative. The parameter $a$ denotes the saving. $b$ is the cost per investment and $c$ denote the elasticity of demands of commercial markets. The factors which are responsible for changing the interest rate $x_{1}$ mainly come from two aspects: first, disequilibrium from the investment market, i.e. the surplus between investment and savings and second, structural adjustment from goods price. The changing rate of $x_{2}$ is in proportion to the rate of investment, and in proportion to an inversion with the cost of investment and interest rates. Changes in $x_{3}$, on the one hand, are controlled by the disequilibrium between supply and demand in commercial markets, and on the other hand, are influenced by inflation rates. Besides these aspects, the average profit margin also influences the changes of interest rate $x_{1}$. The changes of $x_{1}$ is in proportion with the rate of average profit margin $d x_{1}$, where $d$ is a proportionality constant and its value can vary within a certain range. Therefore, based on the system (1), a new chaotic finance system can be generated by adding the average profit margin $\mathrm{dx}_{1}$, then the new threedimensional autonomous equations for chaotic financial system model has the following form [23, 21, 27]:

$$
\left\{\begin{array}{c}
\dot{x_{1}}=x_{3}+\left(x_{2}-a\right) x_{1}+d x_{1} \\
\dot{x_{2}}=1-b x_{2}-x_{1}^{2} \\
\dot{x_{3}}=-x_{1}-c x_{3}
\end{array}\right.
$$

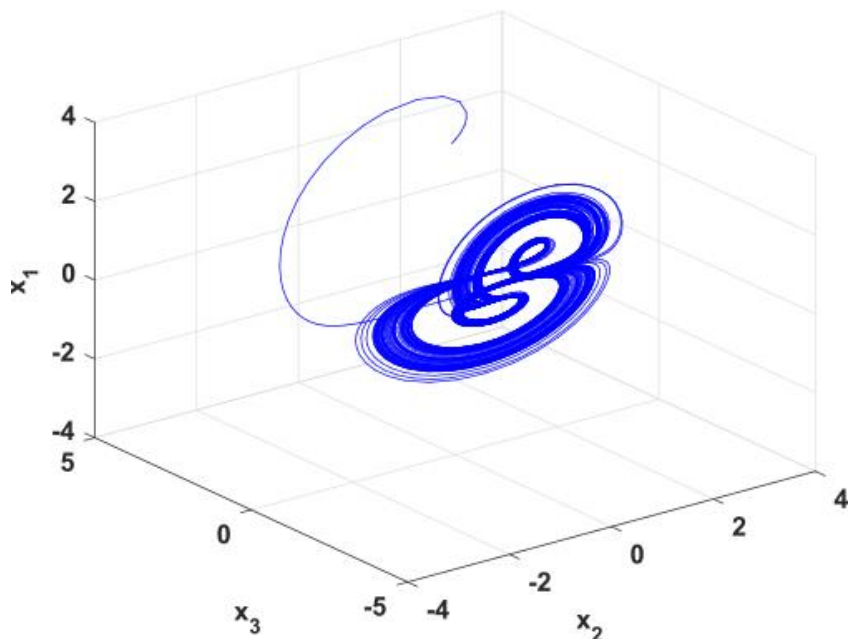

Fig. 3: 3D phase plane of $x_{2}, x_{3}$ and $x_{1}$ in the non-linear chaotic finance system

\subsection{Dynamical Behaviors of the Chaotic Finance System}

Chaotic systems are ultimately bounded [ $31,22,32,33]$ and the phase portraits of the systems will be ultimately trapped in some compact sets. When the parameter values are taken as $a=0.9, b=0.2, c=1.2$ and $d=0.5$, non-linear financial system model (2) exhibits chaotic behavior. The $3 \mathrm{D}$ phase planes of the non-linear chaotic financial system (2) under the initial conditions $x_{1}(0)=1, x_{2}(0)=3$ and $x_{3}(0)=5$ are demonstrated in Fig. 1-3 and the three-dimensional view of the chaotic strange attractors can be seen in Fig. 1-3. The time series response plot is also presented in Fig. 4.
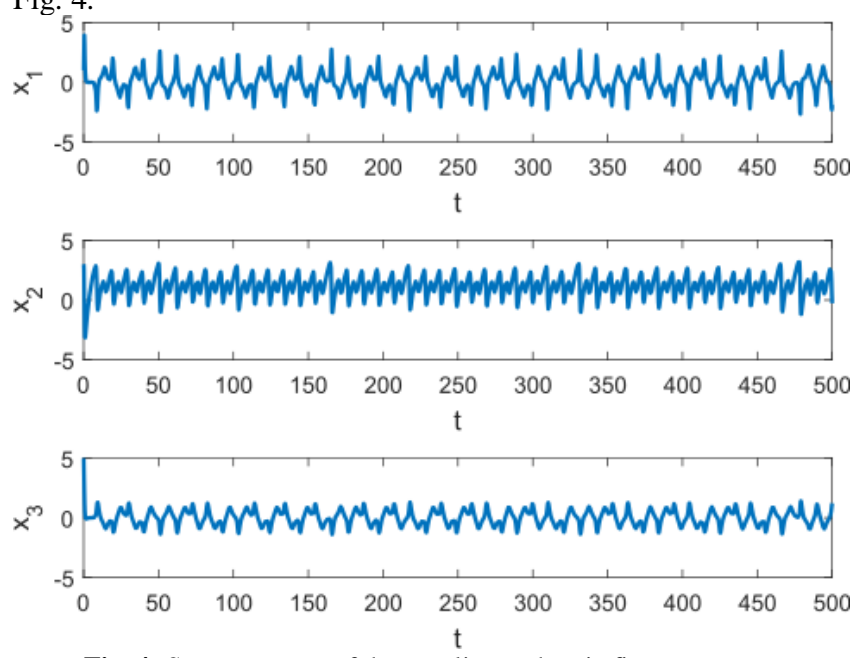

Fig. 4: State response of the non-linear chaotic finance system 
The Lyapunov exponents spectrum are depicted in Fig. 5. For the system parameters $a=0.9, b=0.2, c=1.2$ and $d=0.5$ and the initial conditions $x_{1}(0)=1, x_{2}(0)=3$ and $x_{3}(0)=5$, we obtained Lyapunov exponents $\lambda_{1}=0.048103, \lambda_{2}=-0.055407 \quad$ and $\lambda_{3}=-0.61829$.

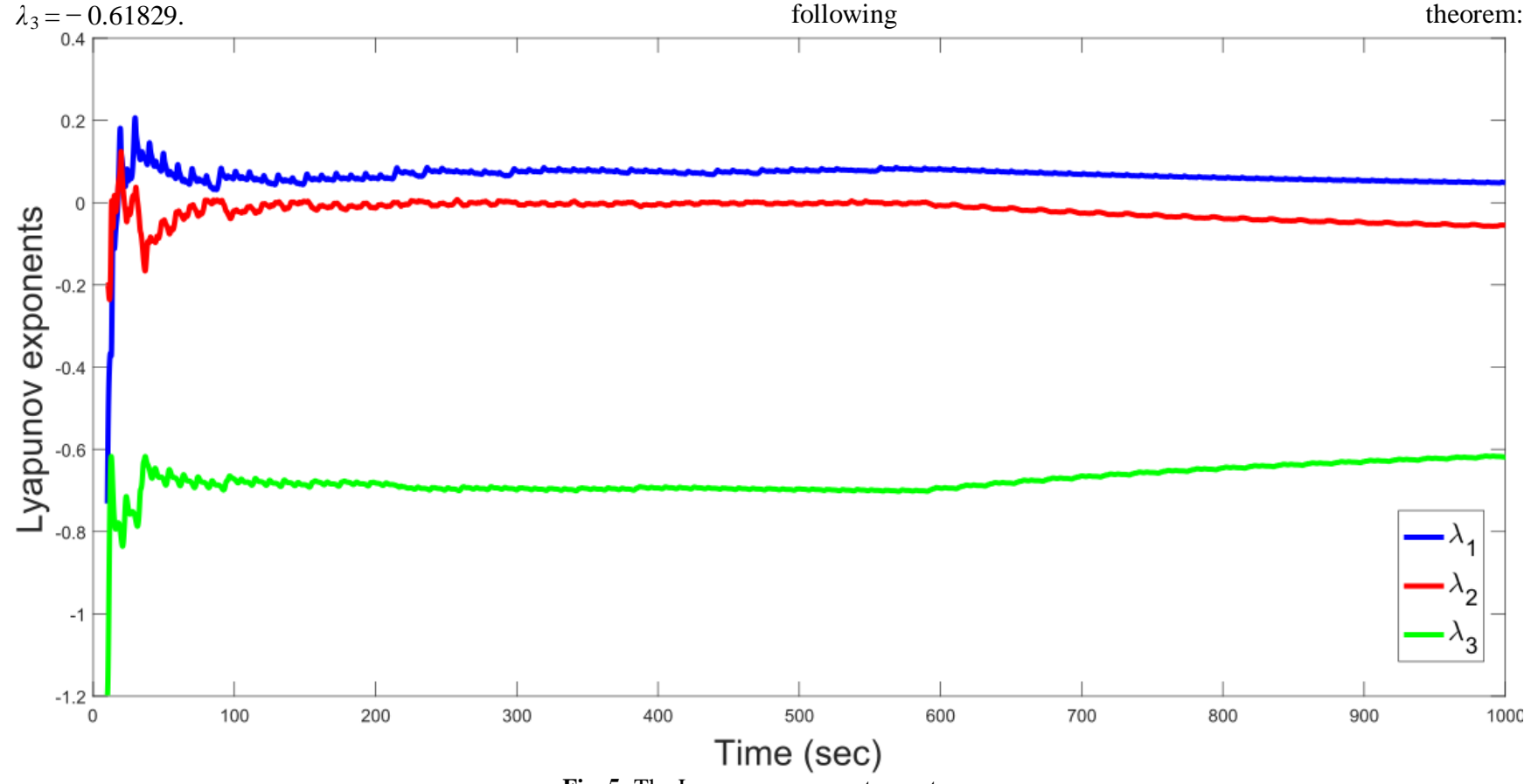

Table 1: Analysis of equilibrium points for non-linear financial system

\begin{tabular}{|c|c|c|}
\hline Existence of stability conditions & Existence of equilibrium points & Stability of equilibrium points \\
\hline $\begin{array}{c}c-b-a b c+b d c<0 \\
c+a-1 / b-d>0\end{array}$ & $\mathrm{P}_{0}(0,1 / \mathrm{b}, 0)$ & Stable convergence \\
\hline $\begin{array}{c}c-b-a b c+b d c<0 \\
c+a-1 / b-d<0\end{array}$ & $\mathrm{P}_{0}(0,1 / \mathrm{b}, 0)$ & Saddle \\
\hline $\begin{array}{c}c-b-a b c+b d c=0 \\
0<c<1\end{array}$ & $\mathrm{P}_{0}(0,1 / \mathrm{b}, 0)$ & Unstable point of the non-hyperbola \\
\hline$c-b-a b c+b d c>0$ & $\begin{array}{c}\mathrm{P}_{0}(0,1 / \mathrm{b}, 0), \\
\mathrm{P}_{1,2}( \pm \mathrm{r},(1+\mathrm{ac}-\mathrm{dc}) / \mathrm{c}, \mp \mathrm{r} / \mathrm{c}) \\
\text { where } \mathrm{r}=\sqrt{(\mathrm{c}-\mathrm{b}-\mathrm{abc}+\mathrm{bdc}) / \mathrm{c}}\end{array}$ & $\begin{array}{c}\mathrm{P}_{0} \text { is stable, } \\
\mathrm{P}_{1,2} \text { are unstable }\end{array}$ \\
\hline
\end{tabular}

Theorem 1: All solution of the non-linear chaotic finance system

(2) with parameters are globally bounded for time $t$

Proof: Consider the Lyapunov function candidate

$\mathrm{V}\left(\mathrm{x}_{1}, \mathrm{x}_{2}, \mathrm{x}_{3}\right)=\frac{1}{2}\left(\mathrm{x}_{1}^{2}+\mathrm{x}_{2}^{2}+\left(\mathrm{x}_{3}^{2}-\mathrm{a}\right)^{2}\right)$

The derivative of $\mathrm{V}\left(\mathrm{x}_{1}, \mathrm{x}_{2}, \mathrm{x}_{3}\right)$ along the trajectory of (2) is given by

$$
\begin{gathered}
\dot{V}=x_{1} \dot{x_{1}}+x_{2} \dot{x_{2}}+\left(x_{3}-a\right) \dot{x_{3}} \\
=x_{1}\left(x_{3}+\left(x_{2}-a\right) x_{1}+d x_{1}\right)+x_{2}\left(1-b x_{2}-x_{1}^{2}\right) \\
\quad+\left(x_{3}-a\right)\left(-x_{1}-c x_{3}\right) \\
=-(a-d) x_{1}^{2}+a x_{1}-b x_{2}^{2}+x_{2}-c x_{3}^{2}+c^{2 a x_{3}} \\
\Rightarrow \dot{V}=-e x_{1}^{2}+a x_{1}-b x_{2}^{2}+x_{2}-c x_{3}^{2}+c_{3}(\text { here }=a-d)
\end{gathered}
$$

Hence, one can construct the following inequality

$$
a\left(x_{1}-\frac{1}{2}\right)^{2}+b\left(x_{2}-\frac{1}{2 b}\right)^{2}+c\left(x_{3}-a\right)^{2}>\frac{1}{4 b}+\frac{e}{4}+\frac{c^{2}}{4}
$$

for any sufficiently large $\mathrm{k}_{0}$ to satisfy $\dot{\mathrm{V}}\left(\mathrm{x}_{1}, \mathrm{x}_{2}, \mathrm{x}_{3}\right)<0$ provided that $\left(\mathrm{x}_{1}, \mathrm{x}_{2}, \mathrm{x}_{3}\right)$ satisfy $\mathrm{V}\left(\mathrm{x}_{1}, \mathrm{x}_{2}, \mathrm{x}_{3}\right)=\mathrm{k}$ with $\mathrm{k}>\mathrm{k}_{0}$.

Consequently, on the surface

$$
\left\{\left(\mathrm{x}_{1}, \mathrm{x}_{2}, \mathrm{x}_{3}\right) \mid \mathrm{V}\left(\mathrm{x}_{1}, \mathrm{x}_{2}, \mathrm{x}_{3}\right)=\mathrm{k}\right\}
$$

where $\mathrm{k}>\mathrm{k}_{0}$, one has $\dot{\mathrm{V}}\left(\mathrm{x}_{1}, \mathrm{x}_{2}, \mathrm{x}_{3}\right)<0$, which implies that the set

$\left\{\left(\mathrm{x}_{1}, \mathrm{x}_{2}, \mathrm{x}_{3}\right) \mid \mathrm{V}\left(\mathrm{x}_{1}, \mathrm{x}_{2}, \mathrm{x}_{3}\right) \leq \mathrm{k}\right\}$ is a trapping region, so that the solutions of chaotic system (2) are globally bounded.
One can observe that there is a positive Lyapunov exponent over a wide range, which implies that the system is chaotic over a broad range. Now, we also consider the fact that the solutions of chaotic system (2) are bounded. This can be justified by the following theorem:

Time (sec) 
transformation of system (2) at the equilibrium point $\mathrm{P}_{1}\left(\mathrm{r}, \frac{1+\mathrm{ac}-\mathrm{dc}}{\mathrm{c}},-\frac{\mathrm{r}}{\mathrm{c}}\right)$ via:

$$
\left\{\begin{array}{c}
X_{1}=x_{1}-r \\
X_{2}=x_{2}-\left(\frac{1+a c-d c}{c}\right) \\
X_{3}=x_{3}+\frac{r}{c}
\end{array}\right.
$$

Using (3) in (2), the following expressions are obtained:

$$
\begin{gathered}
\dot{X_{1}}=\left(X_{3}-\frac{r}{c}\right)+\left(X_{2}+\left(\frac{1+a c-d c}{c}\right)-a\right)\left(X_{1}+r\right) \\
+d\left(X_{1}+r\right)
\end{gathered}
$$

On simplifying and rearranging,

$\Rightarrow \dot{X}_{1}=\frac{\mathrm{X}_{1}}{\mathrm{c}}+\mathrm{rX}_{2}+\mathrm{X}_{1} \mathrm{X}_{2}+\mathrm{X}_{3}$

Now

$$
\begin{aligned}
\dot{X}_{2} & =1-b\left(X_{2}+\left(\frac{1+a c-d c}{c}\right)\right)-\left(X_{1}+r\right)^{2} \\
& =1-\frac{b}{c}-a b+b d-b X_{2}-X_{1}^{2}-2 r X_{1}-r^{2} \\
\Rightarrow X_{2} & =-X_{1}^{2}-2 \mathrm{rX}_{1}-b X_{2}\left(\text { since } r=\sqrt{\frac{c-b-a b c+b d c}{c}}\right)
\end{aligned}
$$

Again,

$\dot{X_{3}}=-\left(X_{1}+r\right)-c\left(X_{3}-\frac{r}{c}\right)$

$\Rightarrow \dot{X}_{3}=-X_{1}-c X_{3}$

Thus, non-linear chaotic financial system defined by (2) is transformed as

$$
\left\{\begin{array}{c}
\dot{X}_{1}=\frac{X_{1}}{c}+r X_{2}+X_{1} X_{2}+X_{3} \\
\dot{X}_{2}=-X_{1}^{2}-2 r X_{1}-b X_{2} \\
\dot{X}_{3}=-X_{1}-c X_{3}
\end{array}\right.
$$

The equilibrium points of transformed system (4) is computed as follows:

$$
\mathrm{E}_{0}(0,0,0), E_{1}\left(-r, \frac{r^{2}}{b}, \frac{r}{c}\right), E_{2}\left(-2 r, 0, \frac{2 r}{c}\right)
$$

The following controlled system formulation is considered to suppress the chaotic behavior of a non-linear financial system (4):

$$
\left\{\begin{array}{c}
\dot{X}_{1}=\frac{X_{1}}{c}+r X_{2}+X_{1} X_{2}+X_{3}+u_{1} \\
\dot{X}_{2}=-X_{1}^{2}-2 r X_{1}-b X_{2}+u_{2} \\
\dot{X}_{3}=-X_{1}-c X_{3}+u_{3}
\end{array}\right.
$$

where $u_{i}(i=1,2,3)$ are external control inputs. By selecting suitable control function $u_{i}(i=1,2,3)$, the chaotic trajectory of system (4) will be steered to the equilibrium point $\mathrm{E}_{0}(0,0,0)$.

The control function $u_{i}(i=1,2,3)$ is formulated by applying Lyapunov stability theorem based adaptive control law.

Theorem 2 (Lyapunov stability for autonomous system): For autonomous system, let $\mathcal{D} \subset \mathcal{R}^{n}$ be a domain containing the equilibrium point of origin. If there exists a continuously differentiable positive definite function $\mathcal{V}: \mathcal{D} \rightarrow \mathcal{R}$ such that

$\dot{\mathcal{V}}=\frac{\partial \mathcal{V}}{\partial \mathrm{x}} \frac{\mathrm{dx}}{\mathrm{dt}}=\frac{\partial \mathcal{V}}{\partial \mathrm{x}} \mathrm{f}(\mathrm{x})=-\mathcal{W}(\mathrm{x})$

is negative semi-definite in $\mathcal{D}$, then, the equilibrium point origin is stable. Moreover, if $\mathcal{W}(x)$ is positive definite, the equilibrium point origin is asymptotically stable.

In addition, if $\mathcal{D}=\mathcal{R}^{n}$ and $\mathcal{V}$ is radially unbounded, i.e.,

$\|x\| \rightarrow \infty \Rightarrow \mathcal{V}(\mathrm{x}) \rightarrow \infty$

Proof of this theorem can be found in [34].
The control function $u_{i}(i=1,2,3)$ can be constructed via following theorem using Lyapunov stability theory.

Theorem 3: The controlled system (5) together with adaptive control law

$u_{i}=-k_{i} X_{i}, \dot{k}_{l}=\gamma_{i} X_{i}^{2}, \quad \gamma_{i}>0(i=1,2,3)$

is asymptotically stable at equilibrium point $E_{0}(0,0,0)$.

Proof: On applying control law (8) into (5), the controlled system (5) can be expressed as follows:

$\left\{\begin{array}{c}\dot{X}_{1}=\frac{X_{1}}{c}+r X_{2}+X_{1} X_{2}+X_{3}-\mathrm{k}_{1} \mathrm{X}_{1} \\ \dot{X}_{2}=-X_{1}^{2}-2 r X_{1}-b X_{2}-\mathrm{k}_{2} \mathrm{X}_{2} \\ \dot{X}_{3}=-X_{1}-c X_{3}-\mathrm{k}_{3} X_{3}\end{array}\right.$

The Jacobian matrix of the system (9) is given by

$J=\left[\begin{array}{ccc}X_{2}-k_{1}+\frac{1}{c} & r+X_{1} & 1 \\ -2 r-2 X_{1} & -b-k_{2} & 0 \\ -1 & 0 & -c-k_{3}\end{array}\right]$

Now, the Jacobian matrix $\mathrm{J}$ is evaluated at the equilibrium point $\mathrm{E}_{0}(0,0,0)$ and it is given by

$\left.J\right|_{\left(\mathrm{X}_{1}=\mathrm{X}_{2}=\mathrm{X}_{3}=0\right)}=\left[\begin{array}{ccc}-k_{1}+\frac{1}{c} & r & 1 \\ -2 r & -b-k_{2} & 0 \\ -1 & 0 & -c-k_{3}\end{array}\right]$

We want to show that the trajectory of the controlled system approaches this equilibrium set as $\mathrm{t} \rightarrow \infty$, which means that the adaptive controller succeeds in regulating $X_{i},(i=1,2,3)$ to zero. Consider the Lyapunov function candidate

$\mathrm{V}=\frac{1}{2}\left(\mathrm{X}_{1}^{2}+\mathrm{X}_{2}^{2}+\mathrm{X}_{3}^{2}\right)+\frac{1}{2}\left[\frac{\left(\mathrm{k}_{1}-\widehat{\mathrm{k}_{1}}\right)^{2}}{\gamma_{1}}+\frac{\left(\mathrm{k}_{2}-\widehat{\mathrm{k}_{2}}\right)^{2}}{\gamma_{2}}+\frac{\left(\mathrm{k}_{3}-\widehat{\mathrm{k}_{3}}\right)^{2}}{\gamma_{3}}\right]$

where $\widehat{\mathrm{k}_{1}}, \widehat{\mathrm{k}_{2}}$ and $\widehat{\mathrm{k}_{3}}$ are the estimates of $\mathrm{k}_{1}, \mathrm{k}_{2}$ and $\mathrm{k}_{3}$, respectively by virtue of (11).

The derivative of $\mathrm{V}$ with respect to time along the trajectory of the system is given by

$$
\begin{aligned}
& \dot{\mathrm{V}}=\mathrm{X}_{1} \dot{\mathrm{X}}_{1}+\mathrm{X}_{2} \dot{\mathrm{X}}_{2}+\mathrm{X}_{3} \dot{\mathrm{X}}_{3}+\left(\mathrm{k}_{1}-\widehat{\mathrm{k}_{1}}\right) \mathrm{X}_{1}^{2}+\left(\mathrm{k}_{2}-\widehat{\mathrm{k}_{2}}\right) \mathrm{X}_{2}^{2}+ \\
& \left(\mathrm{k}_{3}-\widehat{\mathrm{k}_{3}}\right) \mathrm{X}_{3}^{2} \\
& =\mathrm{X}_{1}\left(\frac{\mathrm{X}_{1}}{\mathrm{c}}+\mathrm{rX}_{2}+\mathrm{X}_{1} \mathrm{X}_{2}+\mathrm{X}_{3}-\mathrm{k}_{1} \mathrm{X}_{1}\right)+\mathrm{X}_{2}\left(-\mathrm{X}_{1}^{2}-2 \mathrm{rX}_{1}-\right. \\
& \left.\mathrm{bX}_{2}-\mathrm{k}_{2} \mathrm{X}_{2}\right)+X_{3}\left(-X_{1}-c X_{3}-k_{3} X_{3}\right)+\left(k_{1}-\widehat{k_{1}}\right) X_{1}^{2}+ \\
& \left(k_{2}-\widehat{k_{2}}\right) X_{2}^{2}+\left(k_{3}-\widehat{k_{3}}\right) X_{3}^{2} \\
& =\frac{\mathrm{X}_{1}^{2}}{\mathrm{c}}-\mathrm{rX}_{1} \mathrm{X}_{2}-\mathrm{bX_{2 } ^ { 2 }}-\mathrm{cX_{3 } ^ { 2 }}-\widehat{\mathrm{k}_{1}} \mathrm{X}_{1}^{2}-\widehat{\mathrm{k}_{2}} \mathrm{X}_{2}^{2}-\widehat{\mathrm{k}_{3}} \mathrm{X}_{3}^{2} \\
& =-\left(\widehat{\mathrm{k}_{1}}-\frac{1}{\mathrm{c}}-1\right) \mathrm{X}_{1}^{2}-\left(\mathrm{X}_{1}+\frac{\mathrm{rX}_{2}}{2}\right)^{2}-\left(\widehat{\mathrm{k}_{2}}+\mathrm{b}-\frac{\mathrm{r}^{2}}{4}\right) \mathrm{X}_{2}^{2} \\
& -\left(\widehat{\mathrm{k}_{3}}+\mathrm{c}\right) \mathrm{X}_{3}^{2} \\
& \Rightarrow \dot{\mathrm{V}} \leq-\left(\widehat{\mathrm{k}_{1}}-\frac{1}{\mathrm{c}}-1\right) \mathrm{X}_{1}^{2}-\left(\widehat{\mathrm{k}_{2}}+\mathrm{b}-\frac{\mathrm{r}^{2}}{4}\right) \mathrm{X}_{2}^{2}-\left(\widehat{\mathrm{k}_{3}}+\mathrm{c}\right) \mathrm{X}_{3}^{2}
\end{aligned}
$$

When $\widehat{\mathrm{k}_{1}}>\frac{1}{\mathrm{c}}+1, \widehat{\mathrm{k}_{2}}>\frac{\mathrm{r}^{2}}{4}-\mathrm{b}$ and $\widehat{\mathrm{k}_{3}}>-\mathrm{c}$, the inequality (13) can be evaluated as

$\dot{\mathrm{V}} \leq-\left(\widehat{\mathrm{k}_{1}}-\frac{1}{\mathrm{c}}-1\right) \mathrm{X}_{1}^{2}-\left(\widehat{\mathrm{k}_{2}}+\mathrm{b}-\frac{\mathrm{r}^{2}}{4}\right) \mathrm{X}_{2}^{2}-\left(\widehat{\mathrm{k}_{3}}+\mathrm{c}\right) \mathrm{X}_{3}^{2}<0$

Since the Lyapunov function candidate (12) is positive definite and its time derivative is negative definite in the neighborhood of the equilibrium point $\mathrm{E}_{0}(0,0,0)$, therefore the equilibrium point $\mathrm{E}_{0}(0,0,0)$ of controlled system (9) is asymptotically stable via Lyapunov stability theorem. In other words, the trajectory of 
controlled system (9) asymptotically converges to the equilibrium point $\mathrm{E}_{0}(0,0,0)$ with the adaptive control scheme via the parameter estimation.

Remark 1. The Lyapunov function candidate (12) is dependent on a constants $\widehat{\mathrm{k}_{1}}, \widehat{\mathrm{k}_{2}}$ and $\widehat{\mathrm{k}_{3}}$ which are required to satisfy $\widehat{\mathrm{k}_{1}}>\frac{1}{\mathrm{c}}+$ $1, \widehat{\mathrm{k}_{2}}>\frac{\mathrm{r}^{2}}{4}-\mathrm{b}$ and $\widehat{\mathrm{k}_{3}}>\mathrm{c}$. Since in this theorem, the constants $\mathrm{a}, \mathrm{b}, \mathrm{c}$ and $\mathrm{d}$ are uncertain parameters, therefore, we may not know the constants $\widehat{\mathrm{k}_{1}}, \widehat{\mathrm{k}_{2}}$ and $\widehat{\mathrm{k}_{3}}$ explicitly but we know that it always exists. This highlights another feature of Lyapunov's method, namely, in some situations we may be able to assert the existence of a Lyapunov function that satisfies the conditions of a certain theorem even though we may not explicitly know that function.

\section{Numerical Simulation and Results Analysis}

In this section, numerical simulations are demonstrated to verify the effectiveness of the investigated method. To verify the robustness of control scheme against uncertain parameters, two sets of system's parameters:

$$
\begin{array}{ll}
\text { and } & (\mathrm{a}=0.9, \mathrm{~b}=0.2, \mathrm{c}=1.2, \mathrm{~d}=0.5) \\
& (\mathrm{a}=0.6, \mathrm{~b}=0.2, \mathrm{c}=0.9, \mathrm{~d}=0.5)
\end{array}
$$

are selected in this simulation such that non-linear chaotic financial system model (2) exhibits chaotic behavior in the absence of control.

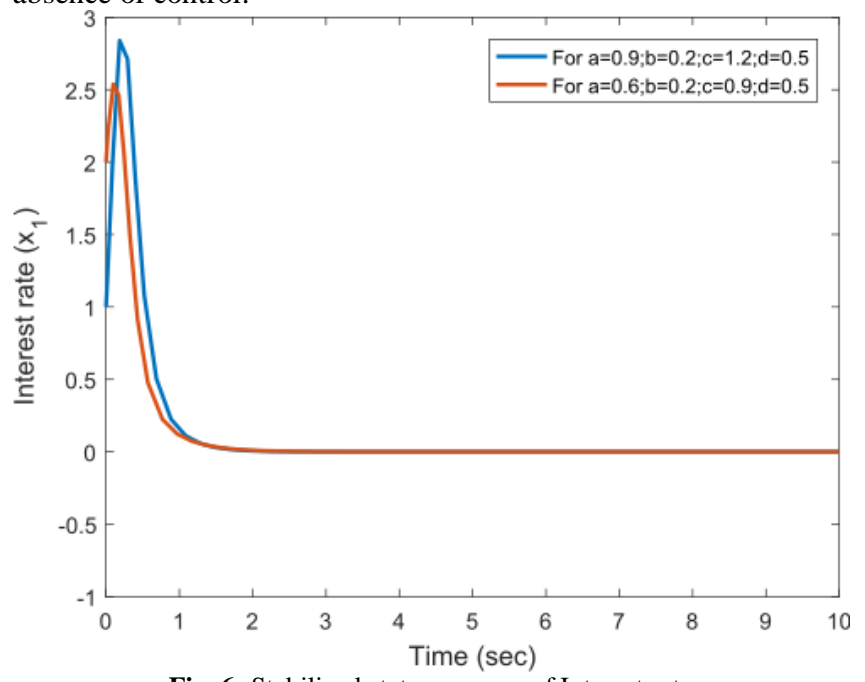

Fig. 6: Stabilized state response of Interest rate

The initial states of controlled system (5) (for both model's parameters) are chosen as

$\left(\mathrm{x}_{1}(0)=1 ; \mathrm{x}_{2}(0)=3 ; \mathrm{x}_{3}(0)=5\right)$

and

$\left(\mathrm{x}_{1}(0)=2 ; \mathrm{x}_{2}(0)=1 ; \mathrm{x}_{3}(0)=4\right)$ respectively. The gain parameters for adaptive control scheme (8) are selected as $\gamma_{1}=1, \gamma_{2}=2.5$ and $\gamma_{3}=1.5$.

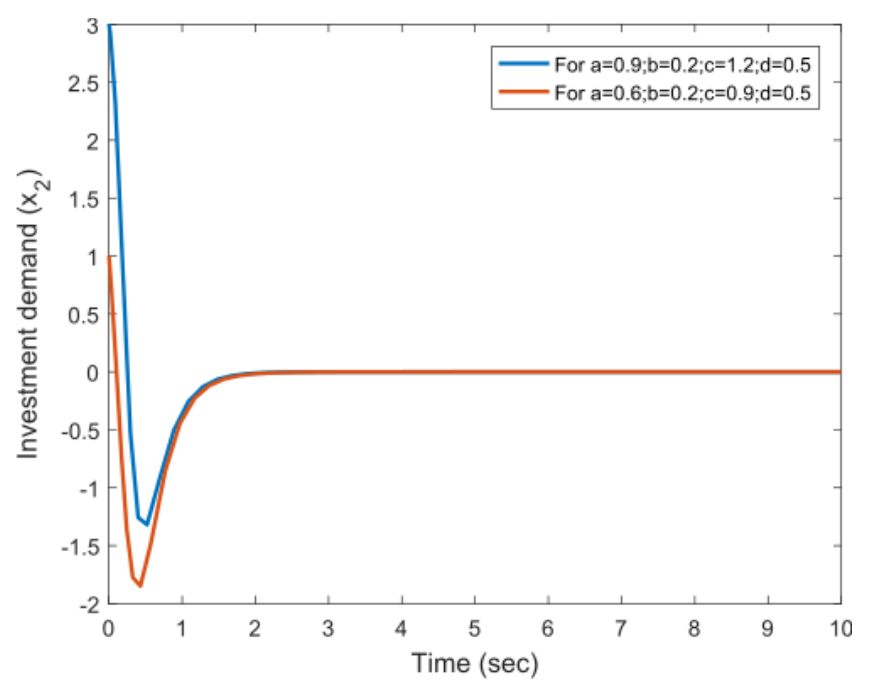

Fig. 7: Stabilized state response of Investment demand

The time response of interest rate $\left(\mathrm{x}_{1}\right)$ of the controlled chaotic financial system is shown in Fig. 6. The Fig. 7 and Fig. 8 illustrate the time response of investment demand $\left(\mathrm{x}_{2}\right)$ and price exponent $\left(x_{3}\right)$ respectively. It can be clearly seen from the Fig. 6, Fig. 7 and Fig. 8 that the adaptive control scheme successfully steer the nonlinear chaotic financial system from initial states (perturbed states) to desired states i.e. [35]equilibrium point $(0,0,0)$. Thus controlled system for non-linear chaotic financial system is asymptotically stable and finally, it can be concluded that the investigated adaptive control scheme is able to control the chaos in non-linear financial system in presence of uncertain parameters.

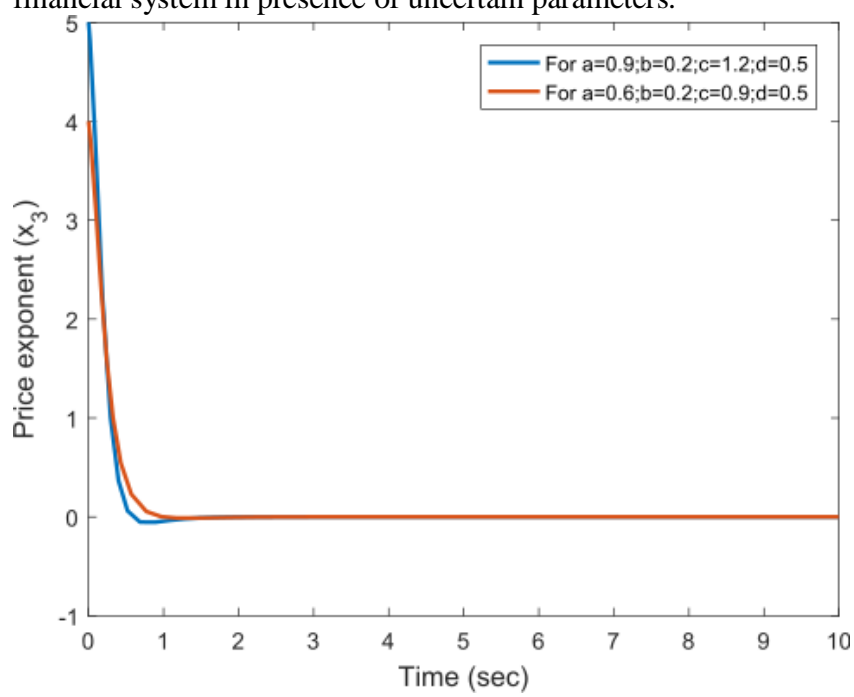

Fig. 8: Stabilized state response of price exponent

\section{Conclusion}

This paper presents an analytical approach for robust stabilization of nonlinear chaotic financial system in the presence of uncertain parameters. The paper first demonstrates the three-dimensional non-linear chaotic financial system model, and its chaotic behaviors via basic system theory concept and then stabilization method are briefly illustrated using Lyapunov stability theory and adaptive control scheme. The numerical simulation in MATLAB/SIMULINK is then provided to show the effectiveness and feasibility of the proposed method. The simulation results of this paper indicate that proposed control scheme is efficient way to adjust and control the interest rate, investment demand and price exponent when chaotic phenomenon appears in the non-linear financial system or economic crisis happens. The proposed control method in this paper is easy to implement and can be extended to other similar systems. It is believed that the chaos control and 
application of chaotic finance system will be studied further in future.[36][37]

\section{Acknowledgements}

The author would like to acknowledge the support of Manipal Institute of Technology, Manipal Academy of Higher Education, Manipal, India. He also wishes to acknowledge Dr. S.K. Mishra, Professor, Department of Mathematics, A.N. College, Patna, for the valuable suggestions on the topic of this paper.

\section{References}

[1] E. Ott, C. Grebogi, and J. A. Yorke, "Controlling chaos," Physical review letters, vol. 64, no. 11, p. 1196, 1990.

[2] Z.W.-H. Cai Guo-Liang, Tan Zhen-Mei and T. Wen-Tao, "Dynamical analysis of a new chaotic system and its chaotic control," Acta Physica Sinica, vol. 56, no. 11, p. 6230, 2007.

[3] J. Lu, G. Chen, and S. Zhang, "The compound structure of a new chaotic attractor," Chaos, Solitons and Fractals, vol. 14, no. 5, pp. 669-672, 2002.

[4] D. Guegan, "Chaos in economics and finance," Annual Reviews in Control, vol. 33, no. 1, pp. 89-93, 2009.

[5] G. Cai and J. Huang, "A new finance chaotic attractor," International Journal of Nonlinear Science, vol. 3, no. 3, pp. 213220, 2009.

[6] I. Evstigneev and M. Taksar, "Dynamic interaction models of economic equilibrium," Journal of Economic Dynamics and Control, vol. 33, no. 1, pp. 166-182, 2009.

[7] G. Chen and X. Dong, "From chaos to order-perspectives and methodologies in controlling chaotic nonlinear dynamical systems," International Journal of Bifurcation and Chaos, vol. 3, no. 06, pp. 1363-1409, 1993.

[8] R. Genesio and A. Tesi, "Control techniques for chaotic dynamical systems," Kybernetika, vol. 29, no. 5, pp. 469-478, 1993.

[9] Surendar, A. (n.d.). Short communication: Role of Microbiology in the Pharmaceutical \&Medical Device. 433| International Journal of Pharmaceutical Research, 10(3).

[10] G. Chen and X.-N. Dong, "On feedback control of chaotic continuous-time systems," Circuits and Systems I: Fundamental Theory and Applications, IEEE Transactions on, vol. 40, no. 9, pp. 591-601, 1993.

[11] K. Kemih, M. Halimi, M. Ghanes, H. Fanit, and H. Salit, "Control and synchronization of chaotic attitude control of satellite with backstepping controller," The European Physical Journal Special Topics, vol. 223, no. 8, pp. 1579-1589, 2014.

[12] C.-C. Fuh and H.-H. Tsai, "Control of discrete-time chaotic systems via feedback linearization," Chaos, Solitons \& Fractals, vol. 13, no. 2, pp. 285-294, 2002.

[13] B. Andrievskii and A. Fradkov, "Control of chaos: Methods and applications. i. methods," Automation and remote control, vol. 64, no. 5, pp. 673-713, 2003.

[14] H. Saberi Nik, P. He, and S. T. Talebian, "Optimal, adaptive and single state feedback control for a $3 \mathrm{~d}$ chaotic system with golden proportion equilibria," Kybernetika, vol. 50, no. 4, pp.596-615, 2014.

[15] A. Y. Leung, X.-F. Li, Y.-D. Chu, and X.-B. Rao, "A simple adaptive-feedback scheme for identical synchronizing chaotic systems with uncertain parameters," Applied Mathematics and Computation, vol. 253, pp. 172-183, 2015.

[16] H. Yu, G. Cai, and Y. Li, "Dynamic analysis and control of a new hyperchaotic finance system," Nonlinear Dynamics, vol. 67, no. 3, pp. 2171-2182, 2012.

[17] S. K. Choudhary, "Lqr based optimal control of chaotic dynamical systems," International Journal of Modelling and Simulation, vol. 35, no. 3-4, pp. 104-112, 2016.

[18] S. Boccaletti, C. Grebogi, Y.-C. Lai, H. Mancini, and D. Maza, "The control of chaos: theory and applications," Physics reports, vol. 329, no. 3, pp. 103-197, 2000.

[19] H. Zhang, D. Liu, and Z. Wang, Controlling chaos: suppression, synchronization and chaotification. Springer London, 2009.

[20] T. Shinbrot, C. Grebogi, E. Ott, and J. A. Yorke, "Using small perturbations to control chaos," Nature, vol. 363, no. 6428, pp. 411-417, 1993.

[21] M. Yang and G. Cai, "Chaos control of a non-linear finance system," Journal of Uncertain Systems, vol. 5, no. 4, pp. 263-270, 2011.
[22] D. Kumar and S. Kumar, "Ultimate numerical bound estimation of chaotic dynamical finance model," in Modern Mathematical Methods and High-Performance Computing in Science and Technology, pp. 71-81, Springer, 2016.

[23] G. L. Cai and M. Z. Yang, "Globally exponentially attractive set and synchronization of a novel three-dimensional chaotic finance system," in 2010 Third International Conference on Information and Computing, vol. 2, pp. 70-73, June 2010.

[24] H. Salarieh and A. Alasty, "Chaos control in an economic model via minimum entropy strategy," Chaos, Solitons \& Fractals, vol. 40, no. 2, pp. 839-847, 2009.

[25] J. Ding and H. Yao, "Chaos control of a kind of non-linear finance system," J. Jiangsu Univ, vol. 15, no. 6, pp. 500-504, 2004.

[26] M. Sun and L.-X. Tian, "Adaptive synchronization of non-linear chaotic finance system [j]," Journal of Jiangsu University (National Science Edition), vol. 6, p. 008, 2005.

[27] A. Jabbari and H. Kheiri, "Anti-synchronization of a modified three-dimensional chaotic finance system with uncertain parameters via adaptive control," International Journal of Nonlinear Science, vol. 14, no. 2, pp. 178-185, 2012.

[28] J. Ding, W. Yang, and H. Yao, "A new modified hyperchaotic finance system and its control," International Journal of Nonlinear Science, vol. 8, no. 1, pp. 59-66, 2009.

[29] W.-C. Chen, "Dynamics and control of a financial system with time-delayed feedbacks," Chaos, Solitons \& Fractals, vol. 37, no. 4, pp. 1198-1207, 2008.

[30] P. He and Y. Li, "Control and synchronization of a hyperchaotic finance system via single controller scheme," International Journal of Intelligent Computing and Cybernetics, vol. 8, no. 4, pp. 330$344,2015$.

[31] P. Wang, D. Li, X. Wu, J. Lü, and X. Yu, "Ultimate bound estimation of a class of high dimensional quadratic autonomous dynamical systems," International Journal of Bifurcation and Chaos, vol. 21, no. 09, pp. 2679-2694, 2011.

[32] P. Wang, Y. Zhang, S. Tan, and L. Wan, "Explicit ultimate bound sets of a new hyperchaotic system and its application in estimating the hausdorff dimension," Nonlinear Dynamics, vol. 74, no. 1-2, pp. 133-142, 2013.

[33] D. Li, J.-a. Lu, X. Wu, and G. Chen, "Estimating the ultimate bound and positively invariant set for the lorenz system and a unified chaotic system," Journal of Mathematical Analysis and Applications, vol. 323, no. 2, pp. 844-853, 2006.

[34] H. K. Khalil and J. Grizzle, Nonlinear systems, vol. 3. Prentice hall New Jersey, 1996.

[35] G, Abikhanova, A Ahmetbekova, E Bayat, A Donbaeva, G Burkitbay (2018). International motifs and plots in the Kazakh epics in China (on the materials of the Kazakh epics in China), Opción, Año 33, No. 85. 20-43.

[36] Akhpanov, S. Sabitov, R. Shaykhadenov (2018). Criminal pre-trial proceedings in the Republic of Kazakhstan: Trend of the institutional transformations. Opción, Año 33. 107-125.

[37] G Cely Galindo (2017) Del Prometeo griego al de la era-biós de la tecnociencia. Reflexiones bioéticas Opción, Año 33, No. 82 (2017):114-133 